九州大学学術情報リポジトリ

Kyushu University Institutional Repository

\title{
Endogenous Agricultural Technology Diffusion with Factor Structural Changes in China
}

Dong, Ying

Department of Agriculture Economics, College of Economics and Management, China Agriculture University

Mu, Yueying

Department of Agriculture Economics, College of Economics and Management, China Agriculture University

Ito, Shoichi

International Food Policy Economist, Faculty of Agriculture, Kyushu University

https://doi.org/10.5109/1543423

出版情報: 九州大学大学院農学研究院紀要. 60 (2)，pp.519-528，2015-09-18. Faculty of Agriculture, Kyushu University

バージョン :

権利関係 : 


\title{
Endogenous Agricultural Technology Diffusion with Factor Structural Changes in China
}

\author{
Ying DONG ${ }^{1}$, Yueying MU' ${ }^{*}$ and Shoichi ITO* \\ International Food Policy Economist, Faculty of Agriculture, Kyushu University, \\ Fukuoka 812-8581, Japan \\ (Received May 7, 2015 and accepted May 19, 2015)
}

\begin{abstract}
Agricultural technology diffusion and its one-way relationship with China's factor structural changes have attracted great attention in recent years. However, most of the previous studies fail to set the diffusion process endogenous to the macro economic development, and are prone to certain conceptual and estimation problems. Our research attempts to take the mutual interaction between agricultural technology diffusion and factor structural changes into account by developing a multi-stage empirical framework, and then using the simultaneous equations model to estimate this endogenous relationship with the provincial level panel data in China from 1991 to 2010. The results indicate that the factor structural changes are impacting China's agricultural technology diffusion. The increasing income of the rural residents and the spurred rural-tourban migration progress along with the technology diffusion may enable the rural residents to converge their food consumption pattern into that of their urban counterpart in the future. Moreover, this derived food consumption structural changes may also adjust the food production resulting in the acceleration of the agricultural technology diffusion.
\end{abstract}

Key words: agricultural technology diffusion, factor structural changes, simultaneous equation model

\section{INTRODUCTION}

There is a close link between factor structures and technology choice in human history. Researchers used to believe that famine were the fate of humanity considering more population with limited natural resources (Johnson, 2000). However, human beings overcome this factor resource shortage challenge through accelerating knowledge transmission and creating relative institutions specifically for resource-saving agricultural technology diffusion (Melody, 1985). In recent decades, many developing economies see the similar situations as structural transformation with the reallocation of input factors. Hence, establishing efficient policy mechanisms has been a priority for these governments in the twenty-first century (Timmer, 2009). During this structural transformation, the induced mechanical technology progress happened in agricultural sector, as an adjustment to rural labor scarcity is playing a crucial role by pushing rural labor out of farm to chase better gain and improving food productivity which keeps a sufficient food supply in spite of rural labor loss. However, this is not the end of the circle. Because the agricultural mechanical technology, which substitutes rural labor, helps the rural-to-urban migration and triggers the recessive structural changes in the rural and urban resident food consumption (Huang, 2010). We believe that these chronic food consumption

- This paper is supported by ["Fruit Vegetables Industry Technology System of Beijing Innovation Team"] the Special Fund for Agro-scientific Research in the Public Interest, China (201103001); Research Fund for the Doctoral Program of Higher Education of China (RFDP) (20120008110032).

Department of Agriculture Economics, College of Economics and Management, China Agriculture University, P.R. China

* Yueying MU and Shoichi ITO are corresponding authors (E-mail: yueyingmu@cau.edu.cn, sito@agr.kyushu-u.ac.jp) structural changes, which in return derives huge changes in food production supply, can entail a new term of factor reallocation and efficiency realization. Therefore, it is of great importance to study this mutual interaction between factor structural changes and agricultural technology diffusion to understand the future agricultural development direction in China.

In recent decades, the structural changes both in the input factor like the quantity shortage and competitive use of labor and land, and in the food consumption triggered by labor migration and cultural integration can be clearly seen in rural China. The agricultural labor loss confronted with increasing quantity and higher quality demand for food leads to an increase in rural labor income with an over 18-fold from 1978 to $2010^{2}$ (Huang, 2010). Specifically speaking, two sources contribute to the income increase. One is the agricultural productivity increase with new technologies, and the other the extra income from the released agricultural labor being employed in non-agricultural sectors which made the rural population size drop precipitously from nearly $95 \%$ in 1978 to about $65 \%$ in 2010 . The migration and the income increase eventually enable the rural residents to shift their old consumption pattern into that of their urban counterpart (Huang and Peng, 2007), which in return, affects agricultural production decision and even the producing input factor reallocation, so does the agricultural technology diffusion in China.

Recent studies have analyzed the motivation, the determinants and the role of agricultural technology diffusion in the economic growth. With respect to the motivation of technology diffusion, the following two hypotheses are dominant: one is the induced technology

\footnotetext{
${ }^{2}$ Calculated by real rural household net income which removed the inflation of CPI.
} 
progress hypothesis proposed by Hicks-Hayami-RuttanBinswanger who proposed that technology diffusion is motivated by related factor shortage, and the other the market demand technology diffusion hypothesis proposed by Schmookler-Griliches who viewed technology as a good to be chosen when its application value is over the market price. These two hypotheses share complementary points and together well explain the actual technology diffusion situation in China (Lin, 1994). In fact, technology diffusion process largely depends on corresponding endowment factors including human capital and information flow (Schultz, 1975), employment creation (De Janvry and Sadoulet, 2001), innovation, entrepreneurship together with the radical uncertainty of political institutions (Fusari and Reati, 2012).

With respect to roles of technology diffusion in the economic growth, Peretto and Seater (2013) emphasize that by spending resources on $\mathrm{R} \& \mathrm{D}$, the constant returns can also be made according to the factor elimination theory. Therefore, to avoid this existing endogenous empirical bias, Berger (2001) extends the agent-based spatial models to analyze the endogenous relationship between technology diffusion and factor changes in certain policies. Xu et al. (2011) provide an endogenous transfer model to describe the process of technology diffusion from R\&D investment to application under the dynamic stochastic general equilibrium, and revalues its contribution to economic growth. Moreover, this interconnection between technology diffusion and economic performance is also captured by Bogliacino and Pianta (2013) using the simultaneous equations model. Furthermore, various technology drivers for factor productivity improvement are introduced into this model to estimate this interaction (Carraro and Enrica, 2013).

Many empirical studies on the developing countries share the thought that the factor structural changes have endogenous effects on agricultural technology diffusion. Kaminski et al. (2013) proposes a structural land-use model to estimate endogenous action between agricultural adoption and the climate change. The studies on the interrelationship between migration behavior and the technological changes in the ways of decision-making by the rural households find that the households that are able to engage in costly high-return migration are more likely to employ modern farming technology (Mendola, 2008) and that they discourage the application of fertilizer due to not only ex-ante credit constraints but also the possibly low consumption outcomes when harvests fail (Dercon and Christiaensen, 2002). However, the gradual food consumption structural changes along with the rural labor migration have received less attention in the literature (Guo et al., 2000; Yu and Abler, 2009).

In conclusion, those previous studies with a model, which can capture this long term hidden consumption structural changes as well as the interaction starting from factor structural changes caused by agricultural technol- ogy diffusion, are relatively rare but of great importance in understanding the future development of structural transformation in China. Since simultaneous equations model is widely used in tackling endogenous problem (Zellner, 1962) and is also well applied in general economic estimation, this research builds a simultaneous equations model system based on the mechanism analysis to estimate this endogenous relationship between technology diffusion and factor structural changes with the consideration of the recessive consumption structural changes.

This research aims at two main objectives. The first is to lay out an empirical framework to systematically describe this endogenous relationships reflected in the multi-stage behavior processes including agricultural technology adoption, production and food consumption. The second is to apply this framework to estimate the interaction between the China's agricultural factor structural changes and agricultural technology diffusion from the perspective of the derived consumption structural changes from 1991 to 2010.

\section{CHANGE IN AGRICULTURAL INPUT OUTPUT AND FOOD CONSUMPTION OF CHINA}

This section presents a general idea in agricultural input factors shortage, agricultural technology diffusion trend and the recessive food consumption structural changes in China. China's rural labor, as a key input factor of agricultural production, is going through a longlasting migration into the urban areas facing a huge wage difference between agricultural and the other industry sectors. Thus, this transfer process not only realizes the efficient use of the rural labor, but also results in a larger income increasing rate of rural residents comparing to urban residents. However, with more agricultural labor loss and the insistent enlarging income gap between the rural and urban residents, China's goal of food security under a stable rural society status has appeared to be threatened. In order to address this salient problem, more agricultural technology adoption is encouraged and more agricultural subsidy policies are implemented to increase food productivity as well as to save more rural labor for more efficient use to fully take advantage of the rapid economic growth in the urban areas.

Figure 1 and Figure $2^{3}$ illustrate the relationship of China's mechanical and biochemical agricultural technology diffusion trends in association with the rural labor and land input changes, respectively, from 1991 to 2010, which give a better understanding of China's food supply conundrum of labor drain, soil nutrient loss, and an increasing food output gain. As shown in figure 1, the rising mechanical technology diffusion is along with the gradually rural labor loss caused by the decrease in the rural birth rate and more off-farm job opportunities during the rapid urbanization process (Huang and Peng, 2007), when mechanical technology substitutes the agri-

Due to the data limitation and the consideration of regional comparability, we selected the 24 provinces except Beijing, Tianjin, Shanghai, Chongqing, Yunnan, Tibet and Xinjiang to calculate indicators in the following parts. 
cultural labor in food producing in the modern agricultural grain planting system. The other source to support this seemingly output miracle is shown in figure 2 as the diffusion of biochemical technology which is mainly presented by the fertilizer input increase here. With better economic return, the other usages such as the cash crops are gradually occupying the original crop land. Hence, more fertilizers are being applied during this period which is mainly used to make up for crop land shrink in grain production. However, as the cropped area continues to be reduced, and the marginal return to the input of fertilizers begins to diminish, the rising demand for grain cannot be met only with fertilizers increasing use. To cater to this demand, the cropped area begins to increase slightly and the fertilizer input turned to work as a complement in grain producing from 2003 to 2010. It is worth noting that the rapid technology diffusion, especially happened in agricultural mechanization, in return, accelerates the rural-to-urban migration process by releasing more rural labor from agricultural production. Some of the released rural labor flowing into the urban areas can access to the benefit of the economic development in the urban areas, and this may enable them to gradually transfer the food consumption pattern into the pattern of their urban counterpart.

To track this derived eating habit changes of rural residents from the perspective of migration income increase, Figure 3 presents the off-farm share in rural resident income (NA share). The rural residents' grain (crude grain) consumption, also the urban residents' grain

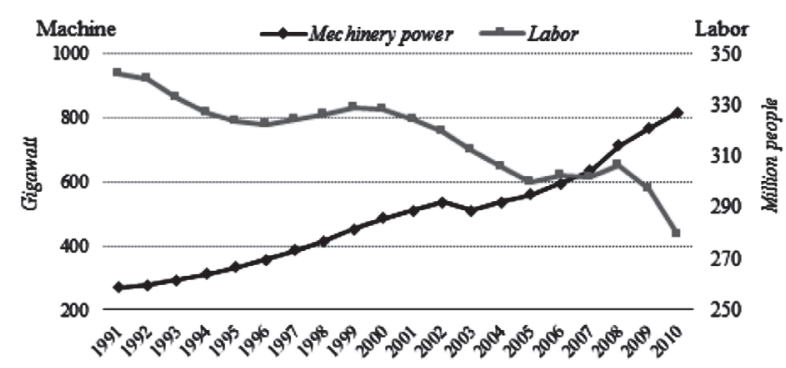

Fig. 1. Mechanical and labor input changes in grain production. Data sources: 1991-2011 China Rural Statistic Yearbook

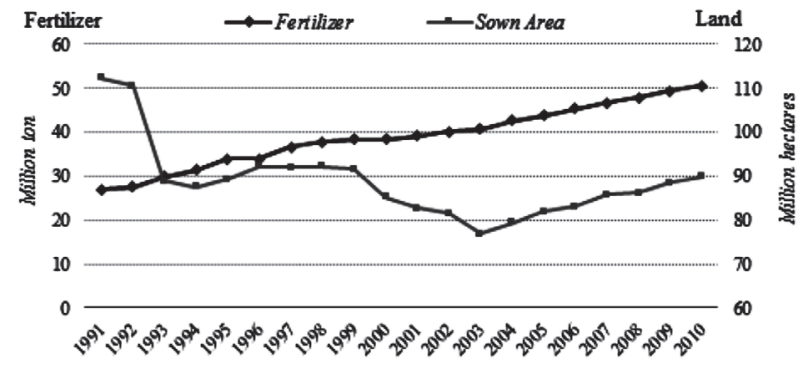

Fig. 2. Fertilizer and land input changes in grain production. Data sources: same as Fig. 1's. (refined grain) consumption can be seen here to help observe the consumption patterns of the two groups comparatively. The overall declining grain consumption trends for both the urban and rural residents can be easily seen during this period. Although the average grain consumption of rural residents is obviously larger than their urban counterpart, their decreasing rate of grain consumption is much higher. The increase in off-farm income share helps to explain this trend well. Since rural residents with more income are more capable of turning to the urban food consumption pattern by shifting their consumption line downwards, this shift may accelerate a grain consumption convergence of the rural-tourban migration people to the urban consumption pattern.

From the statistics above, there come up with several questions: do agricultural input factor structural changes have influence on the diffusion process of the agricultural mechanical and biochemical technology in China? Will the diffusion happen especially in mechanical technology which substitutes for rural labor influence the rural residents' consumption pattern comparatively to the urban residents in the long run? And will the food supply adjustment in response to the consumption structural changes motivate a new term of factor reallocation?

To answer these questions above, we first analyze the interaction mechanism between agricultural technology diffusion and the factor structural changes. Figure 4 presents the specific interaction among factor structural changes, agricultural technology diffusion and the derived consumption structural changes. In the first phase, farmers rationally allocate technological factors under the background of traditional factor resource shortages and regional endowment differences (including education and rural labor mobility levels), which directly contribute to both types ${ }^{4}$ of agriculture technology diffusion. Then the rising agriculture income made by more product output with the help of technology together with the additional off-farm income by released labor is accelerating the consumption pattern change of rural residents and even prompting the food consumption structural convergence

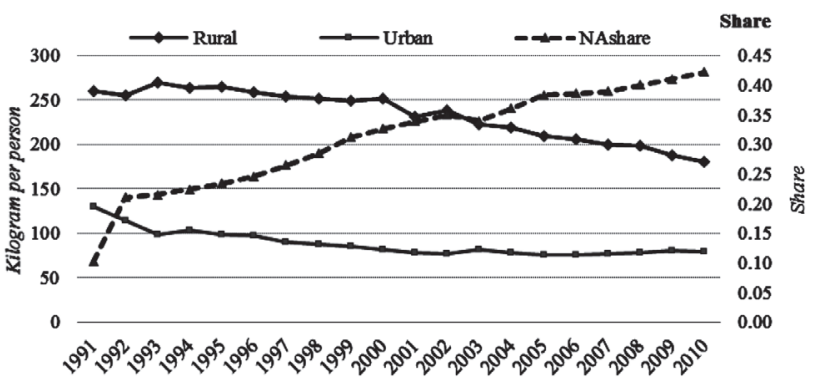

Fig. 3. Non-agricultural income share and grain consumption. Note: NAshare indicates the off-farm income share of the rural residents.

Data sources: 1991-2011 China Rural Statistical Yearbook and China Statistical Yearbook.

\footnotetext{
${ }^{4}$ With more opportunities to work in non-agricultural sectors, farmers may choose to input more biochemical factor to help output more rather than manage by themselves carefully.
} 


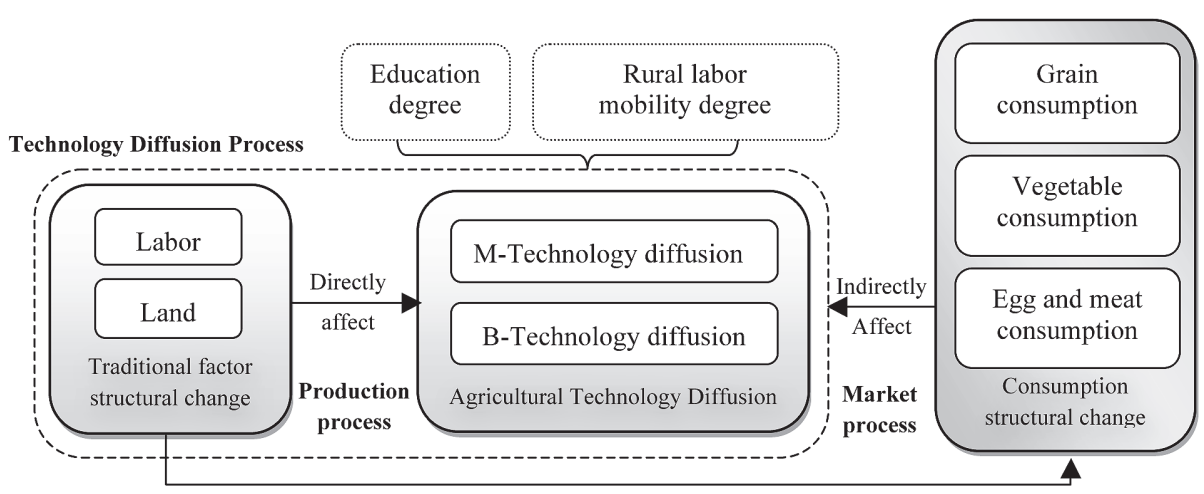

Fig. 4. Interactions of factor structural change and agriculture technology diffusion. Note: the dotted area represents the regional external factors; M represents mechanical and B represents biochemical.

between rural and urban residents. The other way around, this long run recessive food consumption convergence of urban and rural residents may in return impact the food production structure through product market and eventually result in a new term of input factors reallocation and agricultural technology diffusion.

\section{METHODOLOGY}

In this section, we propose an empirical framework to capture the interaction mechanism described above. With the inspiration of the land-use decision model (McGuirk and Mundlak, 1992), this framework is extended from their original model to an economic system composed of three-stage behavior functions: agricultural technology diffusion, production (supply) and food consumption.

\section{Technology diffusion and application behavior}

First, we assume that the behavior of farmers' agricultural technology adoption depends on the farmers' endowments, preferences and technology adoption consistency. Based on the induced technology adoption theory for mechanical and biochemical technologies diffusing with the shortage or comparative use of the endowments, we set the independent variables of labor and land quantity in the specifications below. Besides, taking account of the cognitive level and economy capability for technology adoption, average educational degree ratio and off-farm shares are included as important independent variables. It is worth noting that since secondary and higher education have been proved to promote economic growth in different ways. Specifically speaking, secondary education may work as an input factor to substitute the technological input in producing whereas higher education may contribute to the total factor productivity by motivating the technological adoption (Huang et al., 2013). In addition, to distinguish the provincial aggregate knowledge levels on agricultural management skills, the education variables in stock forms, in other words, the ratios of the educational population in certain level over total population are used here ${ }^{5}$. Off-farm income share represents the opportunity cost of agricultural management which implies the farmers' attitude towards agricultural producing. For example, if the share is high enough, say, the off-farm income can fully cover the cost of the machine application, then farmers would rather allocate their human resources off farm to continuously earn more income and apply more fertilizer instead of doing tech-intensive management to compensate the soil nutrient loss. For more detailed description of the gradually technology adoption behavior process, the function introduces last period diffusion situation as the lag effect to construct the specification as follows:

$$
\begin{aligned}
\ln M_{i t} & =\alpha_{0}+\alpha_{1} \ln L_{i t}+\alpha_{2} \ln K_{i t}+\alpha_{3} \ln M E_{i t}+\alpha_{4} \ln S E_{i t} \\
& +\alpha_{5} \ln N A S_{i t-1}+\alpha_{6} \ln M_{i t-1}+\alpha_{7} t_{2001}+\varepsilon_{0} \\
\ln F_{i t} & =\beta_{0}+\beta_{1} \ln K_{i t}+\beta_{2} \ln M E_{i t}+\beta_{3} \ln S E_{i t} \\
& +\beta_{4} \ln N A S_{i t-1}+\beta_{5} \ln F_{i t-1}+\beta_{6} t_{2001}+\varepsilon_{1}
\end{aligned}
$$

where, $M_{i t}$ : total power of agricultural machinery used in grain production to describe the mechanical technology diffusion situation of province $i$ in year $t ; F$ : quantity of fertilizer used in grain production as a proxy for the biochemical technology diffusion (mainly measured by fertilizer here) situation; $L$ : labor quantity used in grain production; $K$ : sown area of land used in grain production; $M E$ : the proportion of the primary or middle school participators in total population to represent secondary education level; $S E$ : the proportion of the number of students who participate in higher than middle education in total population to denote higher education level; $N A S_{i t-1}$ : lag term of off-farm income share in total income as the farmer's expected opportunity cost based on last year experience; $M_{i t-1}$ : the lag term of mechanical technology

\footnotetext{
${ }^{5}$ We leave the farmers whose education level below the secondary education defined above as the control group here.

${ }_{6}^{6}$ The $\operatorname{lnK}$ is an important variable in specification (1), because lnM is the total power of agricultural machinery which is highly related to the sown area.
} 
adoption; $F_{i t-1}$ : the lag term of biochemical technology adoption; and $t_{2001}$ : dummy variable which is 1 when the period is after 2001 and 0 otherwise. Since China joined WTO and the related Grain Direct Subsidy policy was effective in 2001, food production and even the technology adoption decisions in household level have been largely influenced. In sum, in this stage, both types of the technology diffusions mainly decided by the changes in corresponding traditional input factor are shown in the equations above.

\section{Production and supply behavior}

In this production stage, we maintain the original variables including labor, land and other technology inputs in the Cobb-Douglas production function. Since fertilizer and machine power inputs are closely associated during grain production (Huang and Zhou, 2010), they may not contribute to the output independently. Therefore, their cross-term is used in the specification instead of two separate terms. As we apply the panel data of 20 year length, the agricultural technology progress should be considered here as the time variable. In addition, the disaster factor which greatly affects the final output is also introduced in the specification as follows:

$$
\begin{aligned}
\ln Q_{i t} & =\gamma_{0}+\gamma_{1} \ln L_{i t}+\gamma_{2} \ln K_{i t}+\gamma_{3} \ln F_{i t} \ln M_{i t} \\
& +\gamma_{4} \ln d i s_{i t}+\gamma_{5} t+\varepsilon_{2}
\end{aligned}
$$

where, $Q_{i t}$ : the grain production of province $i$ in year $t$; and $d i s_{i t}$ : the ratio of the disaster area to the sown area of province $i$ in year $t$.

\section{Consumer Demand behavior}

The last phase is for the demand function derived from the consumer utility theory which basically includes income and price index ${ }^{7}$ variables. For income elasticity estimation, the logarithm-reciprocal-logarithm form describing the gradual changing process of food consumption habit with flexible income elasticity especially suitable for Asian countries is adopted (Ito. et al., 1989). The grain consumption changes especially from the increases in income for both rural and urban residents are to be paid more attention, because they are to testify the existence of a food consumption convergence for these two groups. To observe the shift in residents' demand for grain with related food prices, we bring in grain's own prices and other related food price indices. The specifications of the equations are as follows:

$$
\begin{aligned}
\ln D_{u i t} & =\theta_{0}+\theta_{1} \ln I N C_{u i t}+\theta_{2} I N C_{u i t}^{-1}+\theta_{3} \ln P G_{i t} \\
& +\theta_{4} \ln P V_{i t}+\theta_{5} \ln P M_{i t}+\varepsilon_{3}
\end{aligned}
$$

$$
\begin{aligned}
\ln D_{r i t} & =\rho_{0}+\rho_{1} \ln I N C_{r i t}+\rho_{2} I N C_{r i t}^{-1}+\rho_{3} \ln P G_{i t} \\
& +\rho_{4} \ln P V_{i t}+\rho_{5} \ln P M_{i t}+\varepsilon_{4}
\end{aligned}
$$

where, $D_{\text {uit }}^{8}$ and $D_{\text {rit }}$ : the average grain consumption of urban and rural residents, respectively; $I N C_{\text {uit }}$ : average disposable income of urban residents; $I N C_{r i t}$ : average net income of rural residents $P G, P V$; and $P M$ : the market price indices of grain, vegetable, meat and eggs, respectively.

To connect all the above functions together, we assume that the production supply equals to the sum of consumer demand in terms of the product of average demand and population and the stock ${ }^{9}$ shown as follows:

$$
Q_{i t}=\left(D_{\text {uit }} \times P O P_{\text {uit }}+D_{r i t} \times P O P_{r i t}\right)+\text { stock }_{i t}
$$

In conclusion, the equations system to describe the dynamic interaction between the agricultural technology diffusion and factor structural changes is shown as follows:

$$
\mid \begin{aligned}
\ln M_{i t} & =\alpha_{0}+\alpha_{1} \ln L_{i t}+\alpha_{2} \ln K_{i t}+\alpha_{3} \ln M E_{i t}+\alpha_{4} \ln S E_{i t} \\
& +\alpha_{5} \ln N A S_{i t-1}+\alpha_{6} \ln M_{i t-1}+\alpha_{7} t_{2001}+\varepsilon_{0} \\
\ln F_{i t} & =\beta_{0}+\beta_{1} \ln K_{i t}+\beta_{2} \ln M E_{i t}+\beta_{3} \ln S E_{i t} \\
& +\beta_{4} \ln N A S_{i t-1}+\beta_{5} \ln F_{i t-1}+\beta_{6} t_{2001}+\varepsilon_{1} \\
\ln Q_{i t} & =\gamma_{0}+\gamma_{1} \ln L_{i t}+\gamma_{2} \ln K_{i t}+\gamma_{3} \ln F_{i t} \ln M_{i t} \\
& +\gamma_{4} \ln d i s_{i t}+\gamma_{5} t+\varepsilon_{2} \\
\ln D_{u i t} & =\theta_{0}+\theta_{1} \ln I N C_{u i t}+\theta_{2} I N C_{u i t}^{-1}+\theta_{3} \ln P G_{i t} \\
& +\theta_{4} \ln P V_{i t}+\theta_{5} \ln P M_{i t}+\varepsilon_{3} \\
\ln D_{r i t} & =\rho_{0}+\rho_{1} \ln I N C_{r i t}+\rho_{2} I N C_{r i t}^{-1}+\rho_{3} \ln P G_{i t} \\
& +\rho_{4} \ln P V_{i t}+\rho_{5} \ln P M_{i t}+\varepsilon_{4} \\
Q_{i t}= & \left(D_{u i t} \times P O P_{u i t}+D_{r i t} \times P O P_{r i t}\right)+s_{t o c k}
\end{aligned}
$$

Based on the order and rank condition tests, the above simultaneous equation model system can be identified and solved.

\section{DATA}

The empirical framework listed above is estimated using the panel data collected in the 24 provinces in China from 1991 to 2010. This panel data contains a long period of time to help observe the recessive food consumption structural changes. Among the data, rural grain consumption in quantity, urban grain consumption in value, and all the related food price indices are derived from the China Statistical Yearbook (various editions); all the agricultural input factor in quantity, output value, disaster ratio and the off-farm income share are obtained

\footnotetext{
${ }^{7}$ Because the continuous year prices of grain cannot be found, here we use the price index as the proxy.

8 The urban consumption in quantity which cannot be found is got by expenditure dividing the market price.

${ }^{9}$ Given the limited data of provincial trade, and taking into account of the regional food consumption habit due to their agricultural natural endowments, the regional grain trade is missing here.
} 
Table 1. Summary statistics of variables

\begin{tabular}{lccc}
\hline \multicolumn{1}{c}{ Variable } & Unit & Sample average & Std.Dev. \\
\hline$M$ (total power of machinery) & $G W$ & 909 & 892 \\
$F$ (fertilizer) & $10^{4}$ ton & 163 & 118 \\
$K$ (land) & $10^{3}$ hectare & 3,422 & 2,072 \\
$L$ (labor) & $10^{-2}$ Million & 835 & 1,551 \\
$Q$ (grain output) & thousand ton & 1,857 & 1,189 \\
$D I S$ (disaster ratio) & $\%$ & 6.57 & 1,523 \\
$M E$ (secondary education ratio) & $\%$ & 15.1 & 20.3 \\
$S E$ (higher education ratio) & $\%$ & 0.022 & 0.025 \\
$N A S$ (non-farm income share) & $\%$ & 28.5 & 13.0 \\
$I N C_{u}$ (urban disposable income) & yuan & 6,998 & 4,650 \\
$I N C_{r}$ (rural net income) & yuan & 2,488 & 1,650 \\
$D_{u}$ (urban grain demand) & $k g$ & 88.4 & 19.5 \\
$D_{r}$ (rural grain demand) & $k g$ & 233 & 38.7 \\
$P g$ (grain price index) & Index & 105 & 10.0 \\
$P v$ (vegetable price index) & Index & 105 & 7.67 \\
$P m$ (meet price index) & Index & 101 & 7.42 \\
\hline
\end{tabular}

Note: all the statistics are average level of the 24 provinces in China from 1990 to 2010.

Data sources: 1991-2011 China Rural Statistical Yearbook, China Statistical Yearbook and China Education Statistical Yearbook, several issues for each one of them.

from the China Rural Statistical Yearbook (various editions); secondary and higher education ratios are calculated from the China Education Statistical Yearbook (various editions). The descriptions of the samples' average values and standard deviations are reviewed in Table1.

Though the share of total household expenditures devoted to education in rural China has risen quickly (Yu and Abler, 2009), the provincial average education ratios, especially the higher education ratio in rural areas as shown in Table $1^{10}$, is considerably low with only $0.022 \%$. The off-farm share in rural household income is merely $28.5 \%$ which implies that for the majority farmers in China during those two decades, agricultural producing is the main income source. The average rural household net income is 2,488 yuan, and their grain consumption is 233 kilogram per year, while, in contrast, urban residents earn nearly three times that income on average but consume only about one third that grain per year. This implies that the richer group is less dependent on the consumption of inferior food product as grain and there are huge differences in the rural and urban food consumption patterns along this time period. From the perspective of the price indices, the real grain and vegetable price indices have been increased by $5 \%$, while the real price index in meat and egg product grows relatively slow by only $1 \%$ during this period. With regard to the fluctuations of the variables across the regions and over time, huge fluctuation took place in the rural and urban grain consumption, off-farm income share, grain output, the input factors and the education participation ratios; however, the price indices are comparatively stable. All the situations indicate that China is facing dramatic changes in factor structure along with the food consumption in the dimensions of time and region. Thus, the strategy of the dynamic simultaneous equations model we have selected can gain more accurate results considering the large fluctuations in the value of the independent variables.

\section{RESULTS}

Table 2 shows the results of the simultaneous equations model. Overall, the regression results are good with statistically significant, expected signs of individual estimated coefficients and reasonable $\mathrm{R}$-square values for most of the equations.

The estimation results for the first agricultural technology diffusion progress part show that the coefficient for labor in mechanical technology diffusion is significantly negative, while the coefficients for land in the both types of agricultural technology diffusion are significantly positive. The results imply that the substitute effect of mechanical technology for labor, and the both types of technology work mainly as a compensation for land from 1991 to 2010 as Ruttan and Hayami (1984) found before. In other words, the labor shortage in China does prompt the mechanical technology diffusion process, and soil nutrition loss does induce both more fertilizer and machine input in grain production.

${ }^{10}$ All the incomes and price indices have been removed inflation by dividing the nominal value by accumulate CPI index over these 20 years. 
Secondly, the higher education ratio is significantly positive in the both equations, whereas the secondary education ratio is significantly negative only in the machinery technology diffusion equation. These results are consistent with the findings in Huang et al. (2013) that the participation of secondary education works as

Table 2. Estimation results of simultaneous equations model

\begin{tabular}{|c|c|c|c|}
\hline Dependent variable & Independent variable & Coefficient & Standard error \\
\hline \multicolumn{4}{|c|}{ Agricultural technology diffusion behavior function } \\
\hline \multirow{9}{*}{$\begin{array}{c}\operatorname{lnM} \\
\text { (machinery) }\end{array}$} & $\operatorname{lnL}$ (labor quantity) & $-0.295^{* * *}$ & 0.040 \\
\hline & $\operatorname{lnK}$ (sown area) & $1.05^{* * *}$ & 0.041 \\
\hline & lnME (secondary education ratio) & $-0.267 * * *$ & 0.027 \\
\hline & lnSE (higher education ratio) & $0.0500^{* * *}$ & 0.017 \\
\hline & lnNA ${ }_{-1}$ (non-farm income share lag) & $0.309^{* * *}$ & 0.031 \\
\hline & $\operatorname{lnM}_{-1}$ (total power of machinery lag) & $0.173^{* * * *}$ & 0.017 \\
\hline & t2001 (time dummy for 2001) & $0.341^{* * *}$ & 0.043 \\
\hline & constant & $-0.833^{* * *}$ & 0.194 \\
\hline & $\mathrm{R}^{2}=0.873$ & $\mathrm{~N}=480$ & \\
\hline \multirow{8}{*}{$\begin{array}{c}\operatorname{lnF} \\
\text { (fertilizer) }\end{array}$} & $\operatorname{lnK}$ (sown area) & $0.344^{* * *}$ & 0.029 \\
\hline & lnME (secondary education ratio) & 0.0100 & 0.017 \\
\hline & lnSE (higher education ratio) & $0.037^{* * *}$ & 0.011 \\
\hline & 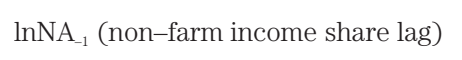 & $0.0400 *$ & 0.020 \\
\hline & $\ln F_{-1}$ (fertilizer lag) & $0.654^{* * *}$ & 0.026 \\
\hline & t2001 (time dummy for 2001) & $0.307^{* * * *}$ & 0.028 \\
\hline & constant & $-0.280 *$ & 0.146 \\
\hline & $\mathrm{R}^{2}=0.936$ & $\mathrm{~N}=480$ & \\
\hline \multicolumn{4}{|c|}{ Production and supply behavior function } \\
\hline \multirow{7}{*}{$\begin{array}{c}\operatorname{lnQ} \\
\text { (output) }\end{array}$} & $\operatorname{lnL}$ (labor quantity) & $0.028^{* * *}$ & 0.008 \\
\hline & $\operatorname{lnK}$ (sown area) & $1.02 * * *$ & 0.031 \\
\hline & lnFlnM (fertilizer×machinery) & $0.006^{* *}$ & 0.003 \\
\hline & lndis (disaster ratio) & $-0.051^{* * *}$ & 0.015 \\
\hline & $\mathrm{t}$ (year) & $0.015^{* * *}$ & 0.002 \\
\hline & constant & $-0.966^{* * *}$ & 0.173 \\
\hline & $\mathrm{R}^{2}=0.960$ & $\mathrm{~N}=480$ & \\
\hline \multicolumn{4}{|c|}{ Consumer demand behavior function } \\
\hline \multirow{7}{*}{$\begin{array}{l}\operatorname{lnDr} \\
\text { (rural average } \\
\text { grain demand) }\end{array}$} & lnINCr (rural net income) & $-0.250 * * *$ & 0.033 \\
\hline & 1/ INCr (the inverse term) & $-166^{* * *}$ & 49.9 \\
\hline & $\operatorname{lnPg}$ (grain price index) & -0.0820 & 0.095 \\
\hline & $\operatorname{lnPv}$ (vegetable price index) & $-0.182^{*}$ & 0.106 \\
\hline & $\operatorname{lnPm}$ (meet and egg price index) & $-0.336^{* * *}$ & 0.114 \\
\hline & constant & $10.2^{* * *}$ & 0.690 \\
\hline & $\mathrm{R}^{2}=0.313$ & $\mathrm{~N}=480$ & \\
\hline \multirow{7}{*}{$\begin{array}{c}\operatorname{lnDu} \\
\text { (urban average grain } \\
\text { demand) }\end{array}$} & lnINCu (urban disposable income) & -0.00200 & 0.033 \\
\hline & $1 / \mathrm{INCu}$ (the inverse term) & $653^{* * *}$ & 144 \\
\hline & lnPg (grain price index) & -0.0150 & 0.089 \\
\hline & $\operatorname{lnPv}$ (vegetable price index) & $0.315^{* * *}$ & 0.100 \\
\hline & $\operatorname{lnPm}$ (meet and egg price index) & -0.146 & 0.108 \\
\hline & constant & $3.59^{* * *}$ & 0.650 \\
\hline & $\mathrm{R}^{2}=0.342$ & $\mathrm{~N}=480$ & \\
\hline
\end{tabular}

Note: $* * *$ implies $1 \%, * *$ implies $5 \%$, and $*$ implies $10 \%$ significance levels. 
the augmentation for labor productivity and the substitute for machine application, whereas the higher education contributes to production indirectly as an incentive factor in technology adoption. The other way to interpret this result is that the farmers with secondary education are often held back from the off-farm job opportunities, so they prefer self-employment in agricultural producing rather than costly mechanical technology investment (Yang et al., 2013). In contrast, farmers with higher education bearing more opportunity cost in labor-intensive planting mode would rather employ more mechanical technology to substitute family human resources. Similar phenomenon can also be seen in biochemical technology adoption where farmers with higher education are inclined to apply more fertilizer to supplement soil nutrient loss. Therefore, the farmers with higher education naturally become the early-adopters of new agricultural technologies.

Thirdly, a previous (lagged) period off-farm share may encourage technology adoption as more income earned from off-farm jobs of the previous period enables the producers to employ more machines and fertilizers in the current term. The significantly positive time dummy variable of the year 2001 shows that the corresponding series of grain subsidies with China's joining in WTO may have a causal effect on farmers' producing decisions. Farmers tend to apply more mechanical and biochemical technology to compensate for labor drain and soil nutrition loss in order to improve productivity and take the challenge from the world food market. Besides, the provinces with higher agricultural technology application rate in the previous period are prone to continue technology diffusion in the current term.

Fourth, for the results of production (supply) at the second stage, the coefficients for labor, land and the cross-term are statistically significant and positive, which indicate not only the fundamental position of labor and land in factor input, but also the complementary roles played together by mechanical and biochemical technology in improving output. Interestingly, we find that land productivity is especially important in output compared to labor, which indicates that China's grain production is land-intensive. As Huang (2013) forecasted, despite of the fact that the rural-to-urban migration can mitigate the pressure from the land-labor ratio to guarantee the majority farmers' income, both labor and land intensive planting mode should be selected to get through the recessive agricultural revolution smoothly. The time variable estimate implies an average total factor progress rate of $1.5 \%$ in output. The estimation result also shows that disaster may harm grain production severely.

Fifth, with respect to the consumer demand behavior estimation results, the constant terms of rural and urban resident grain consumption are 10.2 and 3.59, respectively, indicating that rural residents on average consume more grain than urban resident at the starting point. After further calculation, we get the geometric mean of the income elasticities for rural and urban residents with $-0.134^{11}$ and $-0.155^{12}$ which implies that both rural and urban residents' average demand for grain were falling during this period as their incomes grew. Furthermore, taking the positive sign of inverse urban income and the negative sign of inverse rural income into account, when the income increases, the rural residents' grain income elasticity should continue to fall and the decreasing rate is much faster than that of the urban residents (Zhong and Xiang, 2012; Jia and Zhou, 2013). As a result, this process should accelerate the average grain consumption converge between the rural and urban residents and may indicate a trend that rural residents are quickly catching up although their consumption levels remain comparative lower than their urban counterparts now (Zhang et al., 2008).

Sixth, the results for the price index elasticities of the rural and urban residents are quite different. Among the results, the own-price elasticity for the both rural and urban residents are insignificant which implies that the consumers in China may not be so sensitive to the changes in grain price index nowadays. The estimation results of vegetable cross-price elasticity are -0.182 for rural and 0.315 for urban residents which indicate that the rural residents take vegetable as a complimentary to grain and tend to reduce their grain consumption when the vegetable price increases, while urban residents may consider vegetable as a substitute for grain developing their healthy nutrient intakes from vegetables. This is in line with the research by Li et al. (2012) and Jia and Zhou (2013). However, when the prices of meat and egg rise, rural residents prefer to sacrifice some of their expenditure on grain possibly to maintain their shift food demand for meat and egg (Ma et al., 2004; Zheng and Henneberry, 2012; Jia and Zhou, 2013). In conclusion, besides the negative income elasticity, inner food consumption substitution can also reduce the demand for grain. With respect to the consumption structural trends, although rural residents used to have more demand for grain, they may spend less on grain as the decreasing rate of income elasticity continues along with their income going up. However, the situation is totally different with the urban residents. Despite of their consuming less grain at the base line already, their rising income may slow the decreasing speed of their negative income elasticity leading to a grain consumption convergence between the rural and urban residents.

In conclusion, we find that the quantity shortage and comparative use of labor and land is booming the diffusion process of both mechanical and biochemical agricultural technologies which is in accordance with our expectation. And as a result of mechanical technology diffusion, more income is made both from new technology progress

\footnotetext{
${ }^{11}$ In fact, China rural household often stock grain for consumption (Zhang et al., 2013) which cannot be caught in statistical demand data and may lead to the overestimation the magnitude of the rural residents' grain income elasticity.

${ }^{12}$ Since the outdoor consumption is excepted from the statistical data of urban residents' grain consumption value which underestimate the magnitude of the urban residents' grain income elasticity to a great extent (Li, 2005).
} 
and off-farm income, which accelerates food consumption convergence between rural and urban residents and breaks the old consumption patterns. The other way around, under the market clearing assumption we can further infer that the consumption structural changes including the drastic decline of average grain consumption in the rural residents with less demand and more substitution by other agricultural product is fundamentally changing the original food supply system as indicated by existing literature such as Zhong and Xiang (2012) and Huang and Peng (2007). On the other hand, with the rapid urbanization process and the decreasing of birth rate in rural China, there must be an increasing income trend of the rural residents (Huang, 2010). Given the average falling quantity while the increasing quality demand for grain, it is a good opportunity to conduct the high-value grain producing which may induce more technology adoption as a spillover effect (Rao et al., 2012). In addition, if off-farm employment accounts for more in the rural resident income, then based on our results, the technology diffusion may be further accelerated. Therefore, this producing respond should continue to prompt a new term of reallocation in agricultural technological and traditional factor inputs and affect the factor structural changes in agricultural and the other industries.

\section{SUGGESTION AND FURTHER RESEARCH}

Due to the problems in the availability of continuous data and the derived modeling setting, there are some drawbacks in this research open for future study. With the missing information of off-farm job taken by the released grain producing labor, market clearing condition becomes the only connection of consumption backwards to production decision in our model, and it may not clearly estimate the mutual interaction. In fact, the rural income equation depending on the farm income and off-farm job income should be added into the model system to better quantify this endogenous interaction. Secondly, as our study mainly focuses on grain, more analysis associating with other agricultural products can be considered in order to complete this model system. Furthermore, considering China's regional differences in economic and consumption level, further studies should pay more attention to regional differences or otherwise bring a worldwide and historical view to get a more comprehensive idea of the structural transformation in China by studying the differences and similarities in such process between China and other developed countries which have already gone through this transformation.

Finally, it may take a long time to see the actual consumption pattern convergence between the rural and urban residents, although this is beyond the horizon of this study. However, it is worth digging for the other substantial reasons influencing this consumption convergence. Future studies can also build the relationship between prices and the market or resident income rather than keeping it exogenous to conduct a more flexible empirical model to help explain China's ongoing struc- tural transformation.

\section{REFERENCES}

Azariadis, C. and J. Stachurski 2005 Poverty traps. In "Handbook of economic growth", Vol.1, ed. by Philippe Aghion and Steven N. Durlauf, Princeton University Press, Princeton, pp. 295-384

Berger, T. 2001 Agent-based spatial models applied to agriculture: a simulation tool for technology diffusion, resource use changes and policy analysis. Agricultural economics, 25(2-3): 245260

Bogliacino, F. and M. Pianta 2013 Profits, R\&D, and innovation a model and a test. Industrial and Corporate Change, 22(3): 649-678

Carraro, C. and E. De Cian 2013 Factor-augmenting technical change: an empirical assessment. Environmental Modeling \& Assessment, 18(1): 13-26

Carter, M. R. and C. B. Barrett 2006 The economics of poverty traps and persistent poverty: An asset-based approach. The Journal of Development Studies, 42(2): 178-199

Dercon, S. and L. Christiaensen 2002 Consumption risk, technology adoption and poverty traps: Evidence from Ethiopia. Journal of Development Studies, 38(4): 1-26

De Janvry, A and E. Sadoulet 2011 World poverty and the role of agricultural technology: direct and indirect effects. Journal of Development Economics, 96(2): 159-173

Fusari, A. and A. Reati 2012 Endogenizing technical change: uncertainty; profits; entrepreneurship. A long-term view of sectoral dynamics. Structural Change and Economic Dynamics, 24(3): 76-100

Guo, X., Mroz, T. A., Popkin, B. M., and Zhai, F. 2000 Structural change in the impact of income on food consumption in China, 1989-1993. Economic Development and Cultural Change, 48(4): 737-760

Huang, J. and Zhou, X. 2010 Technical Efficiency and Growth of Total Factor Productivity of Food Production in China: 19782008. South China Journal of Economics, (9):40-52 (in Chinese)

Huang, Y., Yu, L., Yiqun, W. and Wenpu, L. 2013 Economic growth and regional inequality in China: effect of different levels of education. Economic Research, (4): 94-105 (in Chinese)

Huang, P., and Yusheng, P. 2007 The Confluence of Three Historical Trends and the Prospects for Small-Scale Agriculture in China. Social Sciences in China, (4): 74-88 (in Chinese)

Huang, P. 2010 Recessive Agricultural Revolution in China. Law Press, Beijng. (in Chinese)

Huang, P. 2013 Is "Family Farms" the Way to Develop Chinese Agriculture? Open Times, (2): 176-194 (in Chinese)

Ito, S. E. Wesley F. Peterson, and W. R. Grant 1989 Rice in Asia: Is it becoming an inferior good? American Journal of Agricultural Economics, 71(1): 32-42

Jia, J. and Zhou, D. 2013 Forecast of Grain Consumption of China's Urban and Rural Citizens and Structural Optimization: Based on Balanced Nutrition Angle. Agricultural Economics and Management, (1): 55-64 (in Chinese)

Johnson, D. G. 2000 Population, food, and knowledge. The American economic review, $\mathbf{9 0}(1): 1-14$

Kaminski, J., I. Kan and A. Fleischer 2013 A Structural land-use analysis of agricultural adaptation to climate change: A proactive approach. American Journal of Agricultural Economics, 95(1): 70-93

Li, Guoxiang 2005 Estimation of Food Grain Consumption in Chinese Urban Household's Eating out. China Rural Survey, (1): 27-33 (in Chinese)

Li, J. P., and Shangguan, Z. P. 2012 Food consumption patterns and per-capita calorie intake of China in the past three decades. Journal of Food Agriculture \& Environment, 10(2): 201-206

Lin Yifu. 1994 System, Technology and Agricultural Development. Sanlian Publishing House, Shanghai. (in 
Chinese)

Ma, H., Rae, A., Huang, J., and Rozelle, S. 2004 Chinese animal product consumption in the 1990s. Australian. Journal of Agricultural and Resource Economics, 48(4): 569-590

McGuirk, A.M. and Y. Mundlak 1992 The transition of Punjab agriculture: A choice of technique approach. American Journal of Agricultural Economics, 74(1): 132-143

Melody, W. H. 1985 The information society: Implications for economic institutions and market theory. Journal of Economic Issues, 19(2): 523-539

Mendola, M. 2008 Migration and technological change in rural households: Complements or substitutes? Journal of Development Economics, $\mathbf{8 5}$ (1): 150-175

Peretto, P. F and J. J. Seater 2013 Factor-eliminating technical change. Journal of Monetary Economics, 60(4): 459-473

Rao, E. J., Brümmer, B., and Qaim, M. 2012 Farmer participation in supermarket channels, production technology, and efficiency: the case of vegetables in Kenya. American Journal of Agricultural Economics, 94(4): 891-912

Ruttan, V. W., and Hayami, Y. 1984 Toward a theory of induced institutional innovation. The Journal of Development Studies, 20(4): 203-223

Schultz, T. W. 1975 The value of the ability to deal with disequilibria. Journal of economic literature, 13(3): 827-846

Timmer, C. P. 2009 A world without agriculture: The structural transformation in historical perspective. AEI Press. Washington, D.C.

$\mathrm{Xu}, \mathrm{S} ., \mathrm{Z}$. Meng and J. Ling 2011 The technology diffusion, the endogenous technical transformation and China's economic fluctuation. Management World, (3): 004 (in Chinese)

Yang, J., Huang, Z., Zhang, X., and Reardon, T. 2013 The rapid rise of cross-regional agricultural mechanization services in China. American Journal of Agricultural Economics, 95(5): 12451251

Yu X, Abler D. 2009 The demand for food quality in rural China. American Joumal of Agricultural Economics, 91(1): 57-69

Zellner, A., 1962 An efficient method of estimating seemingly unrelated regressions and tests for aggregation bias. Journal of the American statistical Association, 57(298): 348-368

Zhang, R., Wu, L., Carter, C., and Sun, D. 2013 Inflation And Grain Stocks Of Farm Households: Why Don't Farmers Store Grain As Before? In 2013 Annual Meeting, August 4-6, 2013, Washington, DC (No. 150614). Agricultural and Applied Economics Association

Zhang, X., Dagevos, H., He, Y., Van der Lans, I., and Zhai, F. 2008 Consumption and corpulence in China: a consumer segmentation study based on the food perspective. Food Policy, 33(1): $37-47$

Zheng, Z., and Henneberry, S. R. 2009 An analysis of food demand in China: a case study of urban households in Jiangsu province. Applied Economic Perspectives and Policy, 31(4): 873893

Zheng, Z., and Henneberry, S. R. 2012 Estimating the impacts of rising food prices on nutrient intake in urban China. China Economic Review, 23(4): 1090-1103

Zhong, F., and Xiang, J. 2012 The Impact of Urbanization on the Food Demand - Based on the Analysis of Calorie Consumption Perspective. Journal of Agrotechnical Economics, (1): 4-10 (in Chinese)

Zhong, F., and Xiang, J. 2012 Impacts of Demographic Dynamics and Professional Structure on Food Demand. Issues in Agricultural Economy, (9): 12-16 (in Chinese) 